\title{
Problems and Perspective Technologies of the Machinery Complex in the Format of Regional Development
}

\author{
Vladimir V. Moskvichev ${ }^{\mathrm{a}, \mathrm{b}}$ and Natalya A. Chernyakova*a \\ ${ }^{a}$ Institute of Computational Technologies SB RAS \\ Krasnoyarsk Branch Office \\ 53 Mira, Krasnoyarsk, 660049, Russia \\ ${ }^{b}$ Siberian Federal University \\ 79 Svobodny, Krasnoyarsk, 660041, Russia
}

Received 01.11.2019, received in revised form 10.11.2019, accepted 03.12.2019

The state, problems, directions of perspective research and tasks of the modern development of the machinery complex in the strategic planning documents are considered. Research tasks in the field of machine science, structural materials science, general engineering technologies (metalworking, casting, welding), digital industrial technologies, and the safety of technical systems are highlighted based on the concept of non-zero risk of accidents in the field of machinery and equipment used in Siberia, Northern and Arctic regions.

Keywords: machinery complex, engineering, industrial and digital technologies, safety of technical systems.

Citation: Moskvichev V.V., Chernyakova N.A. Problems and perspective technologies of the machinery complex in the format of regional development, J. Sib. Fed. Univ. Eng. technol., 2019, 12(8), 890-902. DOI: 10.17516/1999-494X-0189.

(c) Siberian Federal University. All rights reserved

This work is licensed under a Creative Commons Attribution-NonCommercial 4.0 International License (CC BY-NC 4.0).

* Corresponding author E-mail address: krasn@.ict.nsc.ru 


\title{
Проблемы и перспективные технологии
}

\section{машиностроительного комплекса}

в формате регионального развития

\author{
В.В. Москвичев ${ }^{\text {a, }}$, Н.А. Чернякова ${ }^{a}$ \\ ${ }^{a}$ Институт вычислительных технологий СО РАН \\ Красноярский филиал- \\ Специальное конструкторско-технологическое бюро «Наука» \\ Россия, 660049, Красноярск, пр. Мира, 53 \\ ${ }^{6}$ Сибирский федеральный университет \\ Россия, 660041, Красноярск, пр. Свободный, 79
}

\begin{abstract}
Рассмотрены состояние и проблемы, направления перспективных исследований и задачи современного этапа развития машиностроительного комплекса в постановках документов стратегического планирования. Выделены задачи исследований в области машиноведения, конструкиионного материаловедения, общемашиностроительных технологий (металлообработка, литье, сварка), цифровых промышленных технологий, безопасности технических систем на основе концепции ненулевого риска аварий и в области создания техники и оборудования для регионов Сибири, Севера и Арктики.
\end{abstract}

Ключевые слова: машиностроительный комплекс, машиноведение, производственные и ичифровые технологии, безопасность технических систем.

\section{Введение}

В странах с развитой экономикой объем промышленного производства составляет не менее 50 \% в структуре внутреннего валового продукта (ВВП). В различные периоды социально-экономического развития в XX и начале XXI в. в нашей стране уровень промышленного производства существенно изменялся, характеризуясь спадами в темпах роста (1917-1925 гг.; 1941-1944 гг.; 1991-2015 гг.) и подъемами (1929-1940 гг.; 1946-1990 гг.), когда уровень промышленного производства достигал 60 \% и более. В последние десятилетия данный показатель в структуре ВВП составляет менее $25 \%[1,2]$. На протяжении всех периодов машиностроение рассматривалось как базовая отрасль экономики, определяющая развитие оборонно-промышленного, топливно-энергетического, металлургического, химического, нефтегазового, строительного и других комплексов. Современное состояние машиностроительного производства характеризуется рядом негативных тенденций:

- моральный и физический износ оборудования составляет 60-80\%;

- темпы выбывания оборудования в 3-5 раз превышают темпы ввода новой техники;

- использование основных фондов составляет 30-50 \% от проектной мощности;

- обострение противоречий в системе «человек-машина-среда», проявляющихся в исчерпании проектных и остаточных ресурсов, снижении уровня промышленной безопасности, конструкторско-технологической и общеинженерной культуры проектирования, производства и эксплуатации технических систем и конструкций.

В структуре экспорта доля топливно-энергетических ресурсов составляет $64,7 \%$, машин и оборудования $-5,7 \%$, при этом импорт машин и оборудования $-45,9 \%$. Доля импортного

$$
-891-
$$


оборудования в объеме отраслевой машиностроительной продукции - до 50 \% в металлургии, химической промышленности - 60 \%, в сельхозмашиностроении - до $70 \%$, при этом технологическая независимость страны обеспечивается при уровне импорта менее $25 \%$. Существенное отставание промышленности России от передовых стран сложилось по таким показателям, как инновационная активность предприятий (в 4-5 раз), энерговооруженность работника (3-4 раза), затраты на исследования (4-5 раз) [1].

\section{Документы стратегического планирования}

В сложившейся ситуации правительственными структурами РФ было разработано более 15 федеральных целевых программ, отраслевых стратегий и программ развития машиностроения на период до 2015-2020 гг. Крайне низкий уровень эффективности их реализации не позволил обеспечить выполнение требуемых программных заданий и показателей. Первоочередные задачи нового этапа развития машиностроительного комплекса формулируются в соответствии с установками ряда новых федеральных документов:

- «О стратегическом планировании в РФ» (ФЗ от 28.06.2014 № 172);

- «Стратегия научно-технологического развития РФ» (Указ Президента РФ от 01.12.2016 № 642);

- «О национальных целях и стратегических задачах развития РФ на период до 2024 года» (Указ Президента РФ от 07.05.2018 № 204);

- «Стратегия развития тяжелого машиностроения на период до 2020 года» (Приказ Минпромторга России от 9 декабря 2010 г. № 1150);

- «Стратегия развития транспортного машиностроения Российской Федерации на период до 2030 года» (Распоряжение Правительства РФ от 17 августа 2017 г. № 1756-р);

- «Стратегия развития энергомашиностроения Российской Федерации на 2010 - 2020 годы и на перспективу до 2030 года» (Приказ Минпромторга России от 22 февраля 2011 г. № 206);

- «О безопасности» (ФЗ от 28.12.2010 г. № 390);

• «О промышленной безопасности опасных производственных объектов» (ФЗ от 21.07.1997 № 116);

- нормативные документы Росстандарта, Ростехнадзора, Росатома и др. (ГОСТ, СНиП, СТО, РД, МР).

\section{Направления перспективных исследований и задачи нового этапа}

При создании сложных, крупногабаритных, наукоемких технических систем и инженерных сооружений на основе фундаментальных исследований в области машиноведения, механики деформирования твердого тела, экспериментальной механики, механики деформирования и разрушения, теории безопасности решается значительный комплекс конструкторско-технологических задач в цикле «проектирование-производство-эксплуатация» (рис. 1) и в цикле «материал-технологии-конструкций» [3].

Научно-техническое сопровождение создания инновационной машиностроительной продукции предполагает проведение фундаментальных исследований в традиционных направлениях машиноведения $[4,5]$ : 


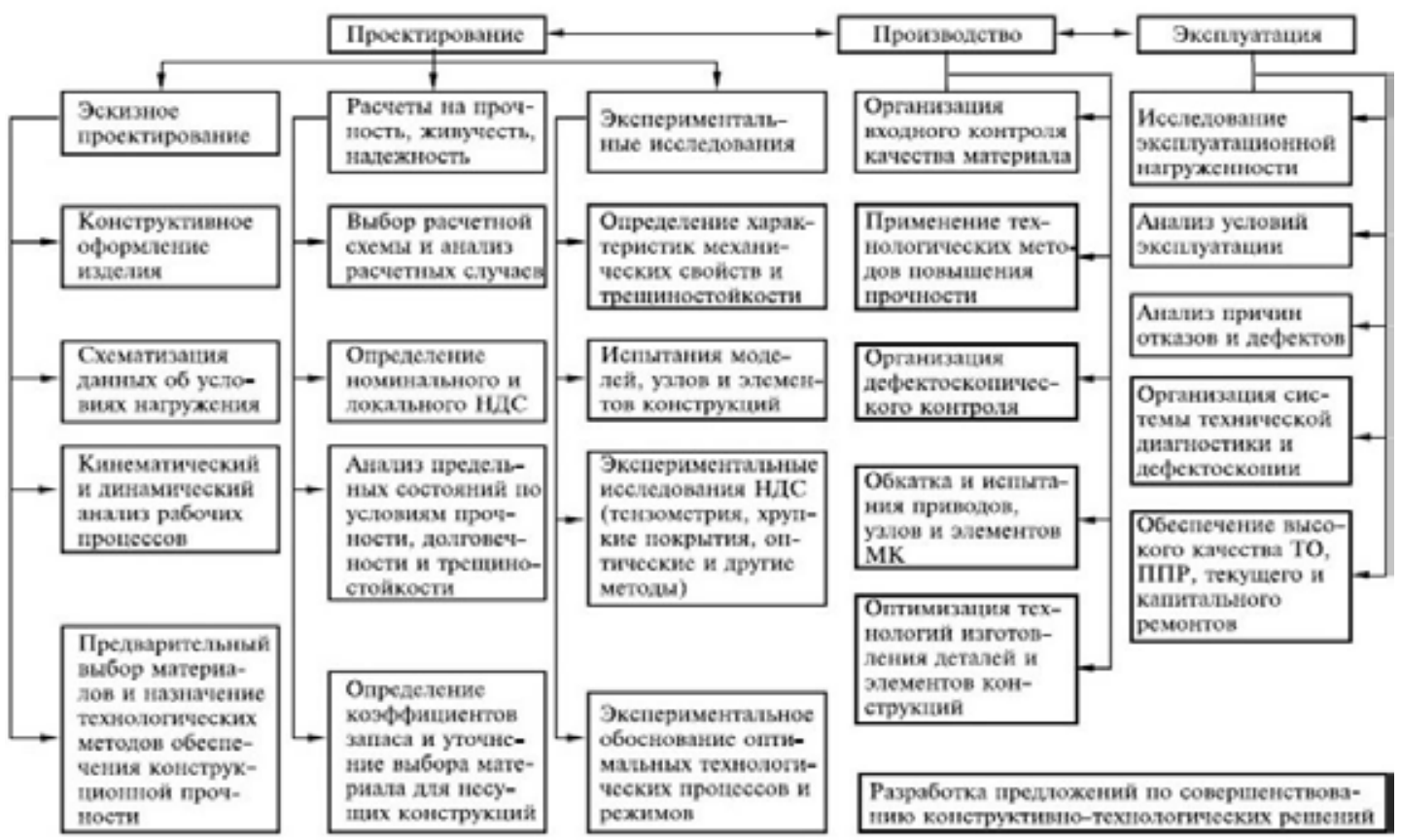

Рис. 1. Основные задачи научно-технического обеспечения в цикле «проектирование-производствоэксплуатация»

Fig. 1. The main tasks of scientific and technical support in «design-production-operation» cycle

- проблемы общемашиностроительных технологий;

- прочность, надежность, ресурс и безопасность технических систем;

- проблемы трения и износа;

- развитие теории механизмов и систем машин;

- проблемы механики и управления в робототехнических системах и автоматизированных производствах;

- колебания и вибромеханика;

- биомеханика.

Наиболее сложные задачи и большой объем исследований и работ приходится на стадию проектирования, при этом выделяются задачи расчетно-экспериментального комплекса:

- Развитие расчетно-экспериментальных методов механики деформирования и разрушения, включая исследования характеристик механических свойств и трещиностойкости, анализ напряженно-деформированных и предельных состояний, моделирование кинетики повреждений, разрушения материалов и конструкций.

- Развитие методов анализа и технологий обеспечения живучести и безопасности технических систем, включая моделирование аварийных ситуаций, оценку и прогнозирование показателей остаточного ресурса, живучести и безопасности, технологические и эксплуатационные технологии обеспечения безопасности.

- Разработка нормативно-технических документов по оценке остаточного ресурса, надежности и безопасности сложных технических систем. 


\section{Задачи в области конструкционного материаловедения:}

- Разработка теоретических основ получения новых конструкционных материалов и технологических процессов, включая материалы с заданными свойствами.

- Создание биметаллических и многослойных материалов и изделий с применением механических и физико-химических воздействий с оптимизацией параметров технологических процессов их производства.

- Создание композитных материалов на металлической и полимерной основе, обеспечивающих значительное снижение массы машин при обеспечении их высокой надежности.

- Разработка технологий получения аморфных мелкодисперсных порошков, волокон и способов их переработки в изделия.

- Создание и широкое использование керамических и композиционных материалов на основе углеводородных волокон, тугоплавких литейных и высокотермостойких полимеров.

Исследования в области общемашиностроительных технологий должны предполагать:

- развитие и разработку новых технологий с использованием высоких и криогенных температур, высоких и импульсных давлений, вакуумных, ионных и других рабочих сред, ультразвука, ионизирующих радиационных излучений (в том числе в условиях космоса), высоких скоростей обработки, электрохимических и электрофизических методов;

- внедрение волновой и вибрационной технологий при производстве металлов и сплавов (рафинирование сталей, управление процессами кристаллизации), обработке деталей (упрочнение, закалка, очистка);

- применение износостойких и антифрикционных покрытий, наносимых вакуумным и ионно-плазменным методами, использование лазерной обработки и других методов поверхностного упрочнения;

- широкое внедрение лазерной технологии для раскроя, термообработки и сварки металлов;

- создание и широкое внедрение мало- и безотходных технологий получения монокристаллических деталей, обеспечивающих снижение материальных и энергетических ресурсов.

Результаты исследований в области металлообработки должны быть направлены:

- на повышение эффективности технологического процесса за счет выполнения на одном станке разнохарактерных операций (точение, фрезерование, сверление и др.), а также совмещенной обработки нескольких поверхностей детали одним инструментом;

- на расширение области применения скоростного резания, скоростного чернового и чистого шлифования, непрерывного протягивания поверхности вместо фрезерования;

- на широкое внедрение комбинированных процессов обработки, основанных на совмещении механического воздействия с тепловыми, химическими, электрическими видами обработки. 


\section{Технологии литейного производства должны обеспечивать:}

- широкое внедрение методов, основанных на использовании высококонцентрированных источников тепла (сжатая электрическая плазма, дуга, электронный луч, ток высокой частоты), вакуума и контролируемых сред, высокоинертных огнеупорных литейных форм;

- применение методов управления тепловыми и силовыми полями при формировании отливки (литье под давлением, направленным затвердеванием, центробежное литье с применением электромагнитных полей) и эффекта вибрационного воздействия при кристаллизации на структуру и свойства сплава;

- повышение плотности и улучшение механических характеристик отливок за счет их обработки в газостатах.

Эффективность технологий сварочного производства может быть обеспечена путем:

- широкого применения ультразвуковой, электронно-лучевой, плазменной, лазерной обработки, обработки световым лучом и трением термопластичных материалов, контактной сварки и пайки;

- исследований, обеспечивающих улучшение свариваемости металлов, повышение прочности и работоспособности сварных соединений, развития методов моделирования процессов сварки и резки металлов.

Цифровые промышленные технологии. Интенсивное внедрение цифровых технологий в промышленное производство предопределяется естественными модернизационными процессами и потребностями научно-технического и технологического развития производительных сил и производственных отношений, приводящих к образованию добавочной стоимости при создании, распределении и потреблении товаров и услуг. Основные приложения в этой области будут развиваться в следующих направлениях:

- высокоавтоматизированное управление всеми аспектами деятельности промышленного предприятия;

- интегрированное высокоавтоматизированное управление созданием товарной продукции на всех этапах жизненного цикла (разработка, производство, эксплуатация);

- интеграция, хранение и интерпретация информационных потоков от источников данных, включая контроллеры АСУТП, сенсоры, программные приложения с использованием моделей цифровых двойников;

- создание и широкое применение систем мониторинга технического состояния промышленного оборудования, технических систем и инженерных сооружений [6].

В промышленном производстве процессы цифровизации будут развиваться с учетом отраслевой специализации и иметь свои особенности при массовом производстве «умной техники», в машиностроении, добыче и транспортировке нефти и газа, в электроэнергетике и т.д. На стадии проектирования машин, технических систем, оборудования и конструкций широкие перспективы связаны с применением компьютерных и вычислительных технологий, в т.ч. цифровых двойников создаваемых объектов и технологических процессов.

В условиях массовой цифровизации существенно возрастет роль материального производства, при этом цифровые технологии и системы, включая материальные объекты и цифровые двойники (модели), представляются средством повышения производительности труда, 
качества выпускаемой продукции, эффективности управления производительными силами и производственными отношениями. Сдерживающим фактором широкомасштабного внедрения цифровых промышленных технологий в машиностроении будут являться отмеченные выше негативные тенденции (повышенный износ оборудования, низкие темпы реновации, технологическая зависимость и т.д.).

\section{Проблемы безопасности технических систем}

При создании высокотехнологичных, наукоемких, сложных технических систем (СТC), обладающих повышенным уровнем опасности, энергетического поражающего потенциала, мощности и металлоемкости возникает проблема безопасности СТС и защищенности природной среды, населения и территорий. Исторический опыт развития техносферы предопределил дилемму научно-технического прогресса:

- высокие темпы развития техносферы в XX веке и выдающиеся достижения (электронная, атомная, космическая, авиационная, энергетическая и химическая техника, генная инженерия и т.д.);

- возникновение и нарастание не существовавших ранее потенциальных и реальных угроз человеку, обществу, среде обитания со стороны объектов техносферы.

Развитие технических систем обуславливает рост числа структурных элементов и управляемых параметров единичной мощности объектов, числа поражающих факторов, ущербов при возникновении катастроф. В этих условиях должен соблюдаться баланс ужесточения нормативных требований обеспечения безопасности СТС и необходимых материально-технических и финансовых ресурсов, включая научное обоснование требований к безопасности СТС. Кризисное состояние возникает при нарушении этого баланса (рис. 2), когда необходимые или затрачиваемые ресурсы не соответствуют и не способны обеспечить требования безопасности.

Традиционные методы обеспечения безопасности СТС за счет избыточной прочности, функциональной избыточности, резервирования и дублирования не предотвращают аварий и катастроф. Для локализации современных техногенных угроз требуются глубокие фундаментальные исследования в области создания систем мониторинга, диагностики, расчетного анализа надежности, остаточного ресурса, защищенности и безопасности СТС. На этой основе формулируется базовая концепция ненулевого риска аварий и катастроф.

Общий уровень безопасности будет определяться параметрами и количественными оценками функций риска $\mathrm{R}(\mathrm{t})$, живучести $\mathrm{L}(\mathrm{t})$, защищенности $\mathrm{Z}(\mathrm{t})$, надежности $\mathrm{P}(\mathrm{t})$, долговечности $\mathrm{T}(\mathrm{t})$ и прочности $\mathrm{F}(\mathrm{t})$ :

$$
\mathrm{S}_{\Sigma}(\mathrm{t})=\{\mathrm{F}(\mathrm{t}), \mathrm{T}(\mathrm{t}), \mathrm{P}(\mathrm{t}), \mathrm{Z}(\mathrm{t}), \mathrm{L}(\mathrm{t}), \mathrm{R}(\mathrm{t})\}
$$

В рамках данной концепции решен ряд практических задач безопасности СТС с использованием результатов технического диагностирования, оценок остаточного ресурса и рисканализа критически важных и потенциально опасных объектов $[7,8]$.

\section{Машиностроение Сибири и создание техники северного исполнения}

Важнейшие государственные решения по развитию Арктической зоны, Сибири и Дальнего Востока ставят новые задачи перед машиностроительным комплексом страны. Организация

$$
-896-
$$




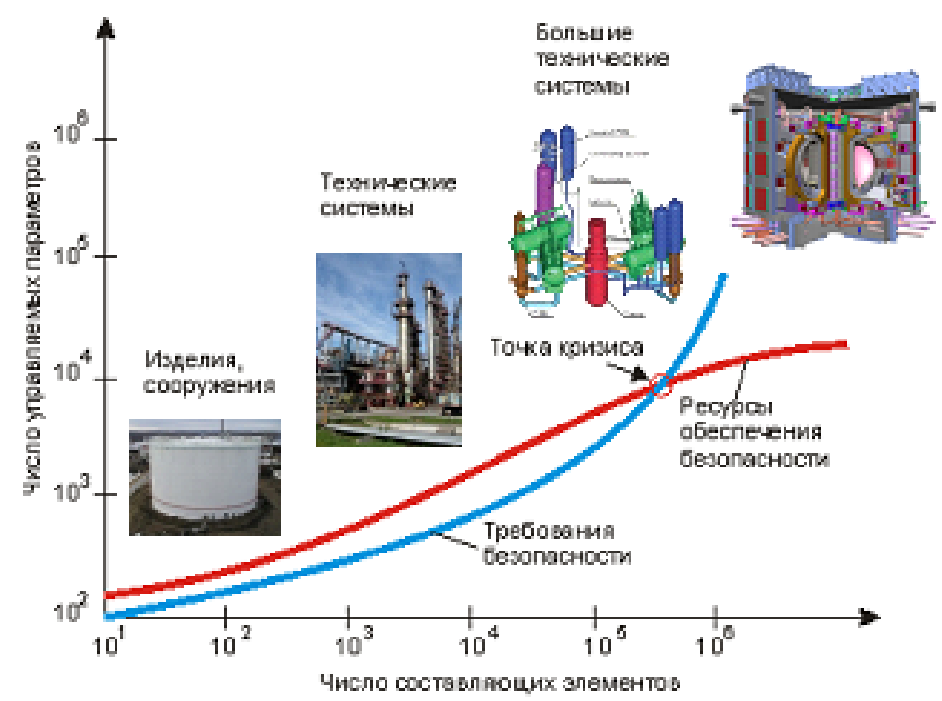

Рис. 2. Тенденции развития технических систем

Fig. 2. Trends in the development of technical systems

массового производства техники северного исполнения на основе современных концепций проектирования, производства и эксплуатации представляется сложной научно-технической, организационной и управленческой проблемой. Повышенная наукоемкость, необходимость междисциплинарного подхода при проектировании, многокомпонентность материаловедческих задач, природно-климатические особенности эксплуатации, сложность анализа причинноследственных связей отказов и разрушений предопределяют особые требования к методам и технологиям создания техники, оборудования и инженерных сооружений северного исполнения (исполнение ХЛ).

Для машиностроительных предприятий Сибирского региона приоритетные задачи, в первую очередь, связаны с реализацией программ и проектов промышленного развития территорий Сибири, Севера и Арктики в области создания техники и оборудования северного исполнения $[5,9]$ :

- разработка и освоение производства отечественной высокопроизводительной и надежной техники исполнения ХЛ, соответствующей экстремальным условиям эксплуатации северных районов, а по техническому уровню - лучшим мировым образцам;

- широкое внедрение прогрессивных технологий, передовых форм организации производства и ремонтно-восстановительных работ, обеспечивающих резкое повышение производительности труда при снижении эксплуатационных затрат;

- организация поставок в регионы с холодным климатом отечественной техники, позволяющей комплексно механизировать производственные процессы при условии частичного отказа от закупки импортных машин и технологического оборудования в исполнении ХЛ.

Решение этих задач возможно на основе частно-государственного партнерства по трем стратегическим направлениям (рис. 3), включая создание производственных мощностей по раз-

$$
-897 \text { - }
$$


витию объектов технологического и инфраструктурного обеспечения с обязательным научнотехническим сопровождением и действием необходимых финансовых механизмов поддержки проектов развития. Во главу угла должно быть поставлено достижение технологической независимости и национальной безопасности на основе мобилизационных, модернизационных и инновационных принципов и механизмов промышленного развития с опорой на отечественное машиностроительное производство продукции гражданского и оборонного назначения. Федеральные законы, концепции и стратегии, принятые в последние годы, ориентируют отечественное машиностроение на достижение устойчивых показателей роста эффективности, производительности труда и объемов выпуска товарной продукции.

Оценка реального состояния машиностроительного производства, анализ приоритетов и прогнозов промышленного развития страны с учетом стратегических рисков жизнедеятельности позволяют сделать вывод о возможности формирования и ускоренной реализации разномасштабных пилотных проектов в машиностроительном комплексе. При этом ключевое значение для будущего страны приобретает станкостроение, роботостроение, энергомашиностроение, атомное энергомашиностроение, транспортное, металлургическое, химическое, сельскохозяйственное машиностроение, машиностроение для лесопромышленного комплекса, производства строительных материалов и строительной техники. Потенциальные возможности отечественного машиностроительного комплекса для решения поставленных задач, несмотря на кризисные явления последних десятилетий в этой области $[1,2,5]$, и его ресурсное обеспечение способны обеспечить реализацию уникальных по своей сложности проектов развития Сибири, Арктики и Дальнего Востока $[1,10,11]$.

В настоящее время основы стратегического развития и производства техники для освоения Сибири и Арктики в соответствии с блок-схемой (рис. 3) формируются на базе машиностроительных отраслей в регионах Урала и Сибири $[10,11]$. После глубокого спада 1990-х гг. в машиностроении Сибири стали проявляться положительные тенденции - рост и реструктуризация производства, обновление производственного аппарата и др. Однако динамика производства в машиностроении региона отличалась неустойчивостью и носила неоднозначный характер. Доля машиностроительного производства СФО в общем машиностроительном производстве РФ составила около 7 \%. Доля машиностроительных производств в общем промышленном производстве СФО не превышала $8 \%$.

Следует отметить, что техническая база действующих предприятий машиностроения Сибири не соответствует мировому уровню техники и технологии производства и не отвечает задачам, стоящим перед экономикой региона. Износ активной части производственного фонда сибирского машиностроения составляет свыше 60 \%. Коэффициент обновления оборудования не превышает $2 \%$. Средний возраст используемого оборудования выше 20 лет, более 60 \% металлорежущих станков и не менее 50 \% кузнечно-прессовых машин имеют возраст 20-25 лет. Современное состояние сибирского машиностроения характеризуется: преобладанием технологий третьего и четвертого укладов, острым дефицитом квалифицированных кадров, низкой рентабельностью производства как на гражданских, так и оборонных предприятиях и морально устаревшей системой управления предприятиями [11].

Анализ перспектив развития машиностроительного комплекса Сибири [11] по инерционному, энергосырьевому и инновационному сценариям показывает, что инновационный путь 

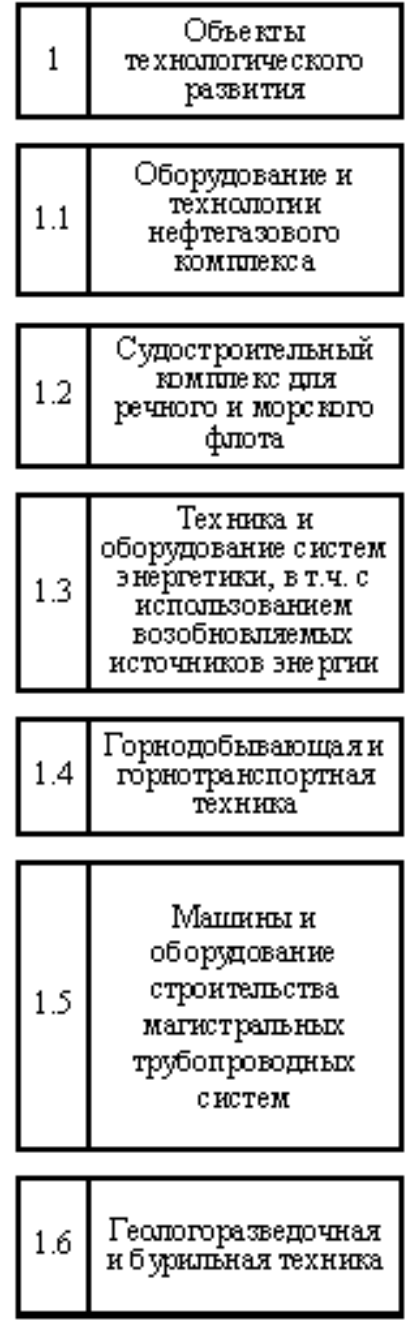
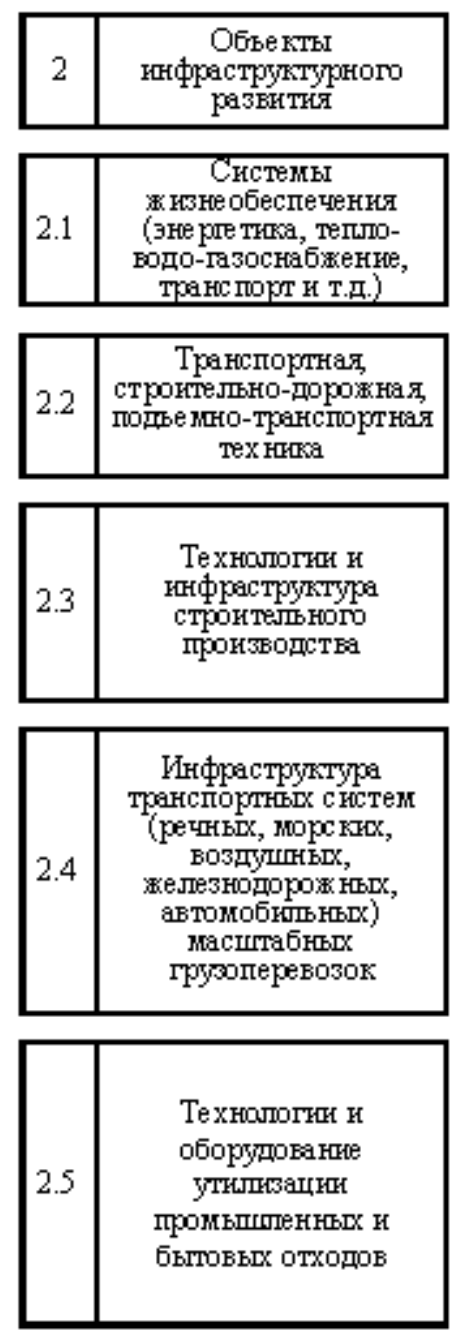
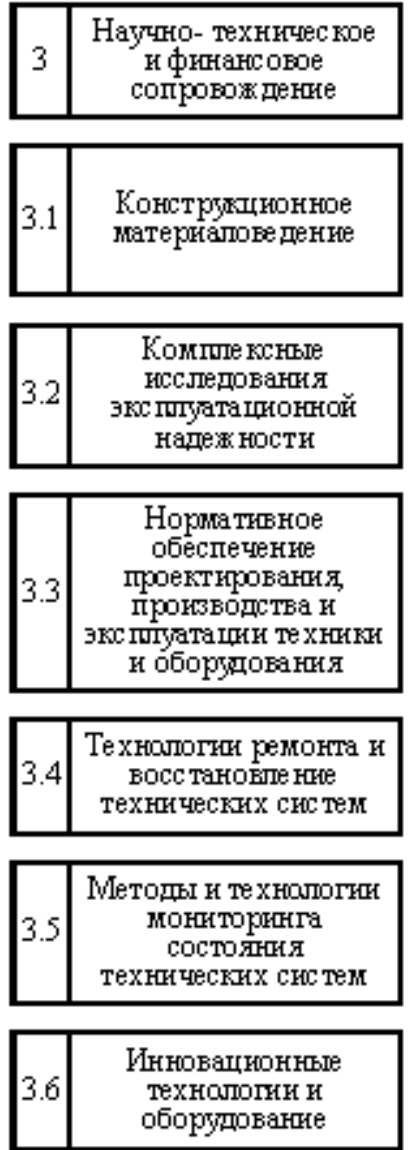

\begin{tabular}{|c|c|}
\hline 3.7 & $\begin{array}{c}\text { Механшзмы } \\
\text { фннансовой } \\
\text { подде ржкт прое ктов } \\
\text { развнти }\end{array}$ \\
\hline
\end{tabular}

Рис. 3. Блок-схема стратегии и объектов развития массового производства техники и оборудования для промышленного освоения Сибири и Арктики

Fig. 3. Block diagram of strategy and objects in the development of mass machinery and equipment production for the industrial growth of Siberia and the Arctic

развития позволяет решить большинство имеющихся проблем. В целом структурные, технологические и организационные преобразования в машиностроении Сибири могут позволить к 2030 г. увеличить объем производства по отрасли более чем в 4,5 раза, в том числе по видам машиностроительной деятельности: в 7,5 раз - по электротехническому, электронному и оптическому оборудованию, в 3,7 раза по транспортным средствам и оборудованию, почти в три раза - по машинам и оборудованию. Формирование образа будущего сибирского машиностроения потребует до 2030 г. 1,5-2,0 трлн руб. (в ценах 2008 г.), направляемых как на модернизацию и обновление предприятий традиционного машиностроения, так и на строительство новых прогрессивных производств.

Более детально в разрезе проектов в области машиностроения для производства техники Сибири и Арктики проблему рассматривала Межрегиональная ассоциация «Сибирское согла-

$$
-899-
$$


шение» (октябрь 2015 г.), в частности координаторы программы «Сибирское машиностроение», в отчетных документах которых дан анализ потенциальных возможностей предприятий СФО в сфере производства продукции для арктических нужд.

\section{Заключение}

Необходимость ускоренного решения обозначенных проблем требует разработки и реализации программ модернизации и развития машиностроительного и производственного потенциала в СФО и его отдельных субъектах. Особое внимание должно быть уделено машиностроительным комплексам Красноярского края, Кемеровской, Новосибирской и Иркутской областей. В дополнение к Стратегиям социально-экономического развития субъектов СФО до 2010 г., разработанных в соответствии с законом «О стратегическом планировании в РФ», целесообразна разработка региональных стратегий развития высокотехнологичного машиностроения на период до 2030 г. С этой целью должны быть решены следующие задачи:

1) оценка состояния и объемов выпуска товарной продукции по видам и отраслям;

2) инвентаризация научно-технического потенциала региона;

3) формирование реестра наукоемких технологий перспективных для использования на предприятиях региона;

4) оценка уровня автоматизации и технологий управления на машиностроительных предприятиях региона;

5) обоснование и формирование программы кадрового обеспечения высокотехнологичных производств по направлениям подготовки специалистов среднего и высшего образования.

Эффективное решение поставленных задач возможно только на базе инновационных научно-технических разработок. Важнейшим условием данного процесса является ускоренное внедрение новых форм и механизмов государственного стимулирования производственной и инновационной деятельности предприятий машиностроительного комплекса по производству техники северного исполнения, к которым с учетом зарубежного опыта [12] можно отнести:

1) государственные программы финансовой и технической поддержки, целевые дотации инновационных предприятий, выполняющих НИОКР по приоритетным направлениям создания новой техники;

2) прямое финансирование (субсидии, займы) до 50 \% расходов на создание новой инновационной продукции и технологий;

3) предоставление ссуд, в том числе без выплаты процентов, а также безвозмездные ссуды на покрытие 50 \% затрат на внедрение новой техники;

4) льготное налогообложение для продукции промышленных инновационных предприятий, в том числе исключение из налогообложения затрат на НИОКР.

Только такой подход даст определенные возможности провести ускоренную модернизацию и формирование нового машиностроительного производства, что позволит обеспечить рост промышленного потенциала всего Сибирского региона. 


\section{Список литературы}

[1] Фортов В.Е., Махутов Н.А. Машиностроение России: состояние и развитие. М.: ОЭММПУ РАН, 2010. 72 c. [Fortov V.E., Makhutov N.A. Russian mechanical engineering: state and development, Moscow, OEMMPU RAS, 2010. 72 p. (in Russian)]

[2] Махутов Н.А., Фортов В.Е. Машиностроение России: перспективы и риски развития. М.: Наука, 2017. 104 с. [Makhutov N.A., Fortov V.E. Russian mechanical engineering: development prospects and risks, Moscow, Nauka, 2017. 104 p. (in Russian)]

[3] Москвичев В.В. Основы конструкиионной прочности технических систем и инженерных сооружений. Новосибирск: Наука, 2002. 106 с. [Moskvichev V.V. Fundamentals of structural strength of technical systems and engineering structures, Novosibirsk, Nauka, 2002. 106 p. (in Russian)]

[4] Махутов Н.А., Петров В.П., Куксова В.И., Москвитин Г.В. Современные тенденции развития научных исследований по проблемам машиноведения и машиностроения. Проблемы машиностроения и автоматизации, 2008, 3, 16-37 [Makhutov N.A., Petrov V.P., Kuksova V.I. Current trends in the development of scientific research on problems of mechanical engineering and machinery. Problems machinery and automation, 2008, 3, 16-37 (in Russian)]

[5] Фортов В.Е., Махутов Н.А., Москвичев В.В., Фомин В.М. Машиностроение России: техника Сибири, Севера и Арктики. Красноярск: Сиб. федерал. ун-т, 2018. 178 с. [Fortov V.E., Makhutov N.A., Moskvichev V.V., Fomin V.M. Russian mechanical engineering: technics in Siberia, the North and the Arctic, Krasnoyarsk, Sib. Fed. Univ., 2018. 178 p. (in Russian)]

[6] Герасимов А. IІоТ, цифровая экономика и цифровая промышленность в России и мире. IIоT. Приложение к журналу «Control Engineering Pоссия». 2019, июнь, 21-27 (https://controlengrussia.com/internet-veshhej/cifrovaja-promyshlennost/; обращение 3.10.2019). [Gerasimov A. IIoT, digital economy and digital industry in Russia and the world, Supplement to the journal «Control Engineering Russia», 2019, June, 21-27 (in Russian)]

[7] Лепихин А.М., Махутов Н.А., Москвичев В.В., Черняев А.П. Вероятностныий рисканализ конструкций технических систем. Новосибирск: Наука, 2003. 174 с. [Lepikhin A.M., Makhutov N.A., Moskvichev V.V., Chernyaev A.P. Probabilistic risk analysis of technical system structures, Novosibirsk, Nauka, 2003. 174 p. (in Russian)]

[8] Доронин С.В., Лепихин А.М., Москвичев В.В., Шокин Ю.И. Моделирование прочности и разрушения несущих конструкций технических систем. Новосибирск: Наука, 2005. 250 с. [Doronin S.V., Lepikhin A.M., Moskvichev V.V., Shokin Y.I. The strength and fracture modeling of the supporting structures of technical systems, Novosibirsk, Nauka, 2005. 250 p. (in Russian)]

[9] Makhutov N.A., Moskvichev V.V., Fomin V.M. Designing machinery for the arctic: a problem of socioeconomic development of Russia's eastern regions $J$. Herald of the Russian Academy of Sciences, 2015, 85(1), 79-86.

[10] Машиностроение Сибири. Сибирь в первые десятилетия ХХІ века. Отв. ред. В.В. Кулешов. Новосибирск: Изд-во ИЭОПП СО РАН, 2008. С. 482-500 [Kuleshov V.V. Mechanical engineering of Siberia. Siberia in the first decades of the $21^{\text {st }}$ century, Novosivirsk, IEOPP SB RAS, 2008. P. $482-500$ (in Russian)]

[11] Амосенок Э.П., Бажанов В.А. Перспективные стратегии развития машиностроения Сибири. Вестник НГУ. Серия: Социально-экономические науки, 2009, 4, 205-214 [Amosenok E.P.,

$$
-901-
$$


Bazhanov V.A. Perspective strategies for mechanical engineering development in Siberia, Vestnik NGU: Series: Social and Economic Sciences, 2009, 4, 205-214 (in Russian)]

[12] Храпов В.Е. Анализ зарубежного опыта инновационного развития машиностроительных предприятий в странах с развитой и переходной рыночной экономикой. Арктика: общество и экономика, 2013, 9, 71-78 [Khrapov V.E. Analysis of foreign experience in the innovative development of engineering enterprises in countries with developed and transitional market economies. Arctic: Society and Economics, 2013, 9, $71-78$ (in Russian)] 